\title{
Macao College Freshman Students' Beliefs and Intentions regarding Learning English as a Foreign Language (EFL): A Theory of Planned Behaviour Perspective
}

\author{
Bo $\mathrm{Hu}^{1}$, Hong Chen ${ }^{2}$, Qiqiang $\mathrm{Xie}^{3} \&$ Yulong $\mathrm{Li}^{1}$ \\ ${ }^{1}$ Foreign Language Education and Research Center, City University of Macau, Macao, China \\ ${ }^{2}$ Faculty of Tourism management and Hospitality, City University of Macau, Macao, China \\ ${ }^{3}$ Department of Teacher Education and Learning leadership, University of Hong Kong, \\ Pokfulam, Hong Kong, China \\ Correspondence: Bo Hu, Foreign Language Education and Research Center, City University \\ of Macau, Avenida Padre Tomás Pereira Taipa, Macau.
}

Received: October 26, 2020 Accepted: November 19, 2020 Published: November 21, 2020

doi:10.5296/ijele.v9i1.17969 URL: https://doi.org/10.5296/ijele.v9i1.17969

\begin{abstract}
This paper investigated Macao college freshman students' English learning under the framework of the Theory of Planned Behaviour (TPB), and a total of 544 valid questionnaire responses were collected for the analyses. Factors like attitudes towards English learning, subjective norms, and perceived behaviour control of Macao college freshmen were analysed with varimax rotation using Principal Component methods. Gender and previous learning places have a significant difference in those factors and their learning intention. The findings showed that the TPB explained Macao college freshman students' English learning beliefs and attitudes. This study provides valuable implications for ways to increase student attitude. English instructors should understand freshman students' English learning intention and adopt efficient teaching methods to increase their motivation.
\end{abstract}

Keywords: English learning intention, attitude, Subjective norms, perceived behavioural control, the theory of planned behaviour 


\section{Introduction}

Following the outline of the National Medium and Long-Term Education Reforms and Development Plan 2010-2020, the internationalisation of higher education has become a significant target in universities of China. Macau, a previous colony of Portugal, now a special administrative region of China, is determined to develop its internationalisation by nurturing talents with efficient English skills. English plays a vital role in Macao as the main business language and is also widely used within the Macao government and organisations at various levels in addition to the two official languages: Chinese and Portuguese. It particularly booms due to the rapid growth of the gambling industry and Macao developing into the World Centre of Tourism and Leisure. According to the 2016 by-census, $2.8 \%$ of Macao citizens use English as their daily language, which is a sharp increase from $2.3 \%$ in 2011 shown from the previous censuses. 27.5\% of Macao citizens could speak fluent English in the 2016 survey, which is also a significant increase from 21.1\% in 2011. Moody (2008) claimed that about $70 \%$ of government websites provide English versions beside Chinese and Portuguese.

Though the topic regarding Macao college students' English learning is well studied in the recent 20 years (e.g., Brayet al. 2002; Young, 2006; Botha, 2013; Ip et al. 2016), the beliefs and attitudes of college students' learning English in the context of higher education internationalisation is under-investigated. Leong \& Li (2011) pointed out that the English language educators' attention in Macao might have been re-directed only to teaching technology and students' learning. Macao students did not realise the increasing status of English, and their enthusiasm for learning English is not high since English may not be so necessary for daily use (Banisaeid \& Huang, 2015). Many studies have demonstrated Macau students' low enthusiasm in English learning and given explanations. Bray et al. (2002) explored the college students' English proficiency. They found that there was still a gap between the local students' English proficiency levels and the English language requirement of the local college institutions since many academic courses were taught in English only. Shi (2006) claimed that Macao students were irresponsible and passive in their learning due to the traditional Confucianism of second language instruction, which underpinned the English teaching in Macao. Young (2006) investigated university students' attitudes towards English after Macao's return to China. She found that the Macao-born students were less comfortable in speaking English and less confident of the superiority of English comparing to the Mainland-born students in Macao where Chinese and Portuguese are official languages. Besides, there was no long-term language policy and English learning campaigns in Macao. Botha (2013) claimed that the students' English level varied overwhelmingly. Such variance was observed in the of first year college classrooms because the medium of instruction in the English Classrooms was quite different in secondary schools. Some other studies showed that the lack of clear goals for teaching and learning. Furthermore, the uniformity in the English education system had weakened the students' English learning motivation and intention (Moody, 2008; Young, 2009; Vong \& Wu, 2010; Fan \& Ho, 2012).

As seen from above, most previous studies investigated Macao students' low English proficiency from the social factors, but few studies have been conducted from Macao students' psychological perspectives. Young (2009) claimed that Macao students learned English due to their instrumental motivation, such as passing exams and finding a good job. Ip et al. (2016) investigated 346 Macao college students' beliefs and their learning strategies 
that Macao college students were generally extrinsically motivated without satisfactory English learning outcomes. Their beliefs on learning English varied from the examination-driven school environment to the boom in the economy. However, these studies mainly focused on the student' extrinsic motivations without exploring their intrinsic motivations.

Furthermore, all the target students in the latter research are from the same university and were mainly less successful learners, so the research findings were not entirely satisfying. Monteiro \& Tchiang (2017) studied five local Chinese secondary schools in Macao and found that many students felt positive about the learning materials, course handouts and activities delivered by their teachers though they felt that their autonomy and self-regulated learning were not encouraged as part of the learning process. However, their study focused on secondary students' English learning from the perspective of psychological factors without a well-grounded theoretical framework. Therefore, it is significant to examine thoroughly intrinsic and extrinsic factors which Macao college students consider important in their English learning.

Under the framework of the Theory of Planned Behaviour (Ajzen, 1985, 1991, 2001, 2002, 2006, 2012), this study examined Macao college freshmen's English learning from the learners' psychological perspective to uncover their attitudes, subjective norms, perceived behavioural control and intentions towards English learning. Besides, previous research suggested that differences exist in TPB variables in terms of gender and past-study places. Therefore, this study looked into Macao college freshmen's gender and past-study place impact on their English learning. In this case, the following three research questions have been investigated:

1) How do Macao College freshman students' attitudes, subjective norms, and perceived behavioural control towards learning English as a foreign language (EFL) affect their English learning behavioural intention?

2) What is the relationship between Macao College freshman students' genders and their attitudes, subjective norms, perceived behavioural control, and behavioural intention toward learning EFL?

3) What is the relationship between Macao College freshman students' places of learners' previous studies and their attitudes, subjective norms, and perceived behavioural control towards learning EFL?

\section{Conceptualising Framework}

\subsection{The Theory of Planned Behaviour}

The Theory of Planned Behaviour (TPB) assumed that intentions to perform behaviours of different kinds could be predicted with high accuracy from attitudes toward the behaviour, subjective norms and perceived behavioural control (Ajzen, 1991). It has become one of the most influential and popular conceptual frameworks for the study of human action (Ajzen, 2001). It focused on individual motivation to perform a certain behaviour and claimed that attitudes, subjective norms, and perceived behavioural control could predict an individual's behaviour since they could influence an individual's behavioural intention. If the attitude and subjective norms are more favourable and the perceived control is greater, an individual's intention to perform the behaviour in question should be stronger (Ajzen, 2006). This study 
used behavioural intention as a dependent variable but not the actual behaviour because intentions are assumed to capture the motivational factors that influence a behaviour and is assumed to be the immediate antecedent of actual behaviour (Ajzen, 2002). Though the TBP was revised a few times, the essential concept has remained constant (Ajzen, 1991, 2001, 2002, 2006, 2012, 2014, Fishbein \& Ajzen, 2011).

\subsection{Attitudes toward a Behaviour}

Attitude explains and predicts an individual's behaviour. Attitudes toward behaviour refer to the degree to which a person has a favourable or unfavourable evaluation or appraisal of the behaviour in question (Ajzen, 1991). It is a kind of psychological good and bad, harmful and beneficial, evaluation of pleasure and unhappiness, like and dislike (Ajzen, 2001). If a person's positive attitude toward behaviour is high, he will be more likely to perform the behaviour. In other words, if an individual perceives that English is interesting and important, he will be more inclined to develop a strong intention to English learning.

\subsection{Subjective Norms}

Subjective norms refer to the perceived social pressure to perform or not to perform a behaviour (Ajzen, 1991). They can be analysed mainly from the viewpoints of other important people like parents, family members, teachers. and their reactions on the behaviour (Haggar \& Chatzisarantis, 2005). The social circle of people may have a big influence on an individual's decision-making and can cause social pressure to make an individual engage in the behaviour. Subjective norms can be further divided into injunctive norms and descriptive norms. Injunctive norms refer to perceptions concerning what ought or should be done. Descriptive norms, on the other hand, refer to other important people's actually performing (or not) the behaviour under consideration (Fishbein and Ajzen, 2011). So in this study, other important people's expectations of a student's English learning and their real performance in English are important determinants in their English learning intention.

\subsection{Perceived Behavioural Control}

Perceived behavioural control refers to the perceived ease or difficulty of performing the behaviour (Ajzen, 1991). It reflects the degree to which an individual is aware of the ease or difficulty in promoting or hindering the implementation of behavioural factors (Ajzen, 2001). Further, it involves an individual's judgement of general ability to perform a behaviour and an individual's responsibility and control over the process of performing a behaviour. The former is defined as self-efficacy; the latter is called as autonomy (Choen et al. 2012). Self-efficacy of English learning enables an individual to have personal judgements on his ability and to evaluate whether they could learn English well or not. Furthermore, Ajzen (2002) also suggested that there is a possible direct path involving perceived behavioural control and behaviour; a high level of perceived control should strengthen a person's intention to perform the behaviour.

\subsection{Behavioural Intention}

Behavioural intention indicates how hard people are willing to try and how much of an effort 
they are planning to use to perform the behaviour (Ajzen, 1991). It refers to the possibility of an individual's subjective probability of taking a particular action, which reflects the individual's willingness to act (Ajzen, 2001). The stronger an individual's intention to perform a behaviour, the more likely he is to perform the actual behaviour. The positive relationship between intention and actual behavior has been affirmed by many relevant studies such as Venkatesh and Davis (2000) and Venkatesh, et al. (2000). However, McEachan et al. (2011) pointed out that some intervening events can change people's behavioural, normative or control beliefs, modify attitude, subjective norms, or perceptions of control, and could finally generate revised intentions. This kind of changes will cause the intention less predictive, so they associate shorter intervals between assessment of intentions and observation of behaviour with stronger correlations than longer time intervals.

The adoption model of the Theory of Planned Behaviour (Ajzen, 1991) in Fig. 1.

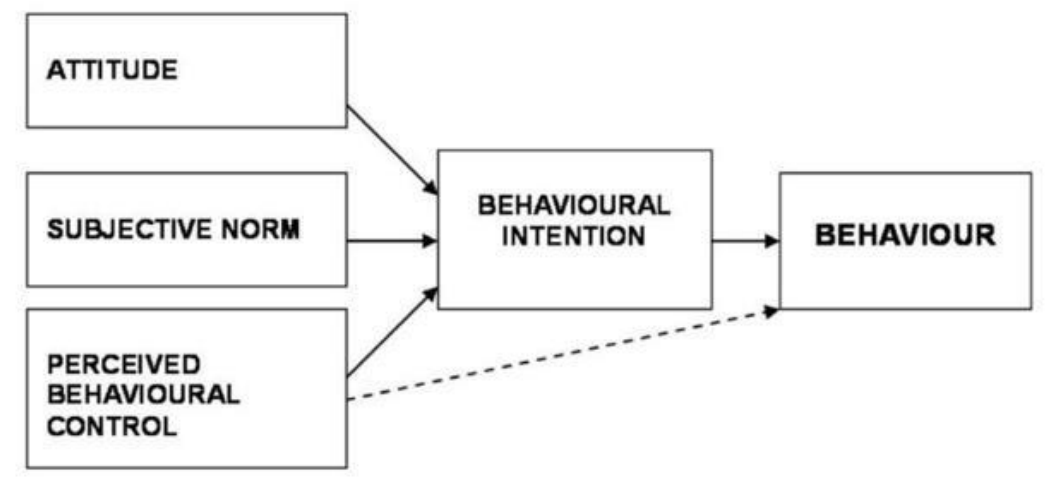

Figure 1

According to Fishbein and Ajzen (2011), the TPB has become a widely accepted framework for explaining and predicting behaviours. It has been of great importance in predicting most of the behaviour-associated actions in different fields, especially in students' learning and teaching behaviours.

Chen (2004) investigated Taiwanese continuing education students' beliefs on language training programs. They found that the strongest variable to predict the behavioural intention was the attitude toward the behaviour followed by perceived behavioural control and subjective norm. Cheon et al. (2012) studied college students' perceptions toward mobile learning in a large public research-intensive university located in the Southwest of United States. It revealed that the students' attitudes concerning m-learning, subjective norm, and behavioural control influenced their intention to adopt m-learning, inferring that the adoption needs should be regarded from different perspectives. Another study on Chinese ESL students' in-class participation revealed that the stronger predictors for students' participation were attitudes toward participation and self-efficacy, and female students had stronger intentions to participate in class (Girardelli \& Patel, 2015). TPB framework was also applied in research to teacher's intentions and behaviour in the classroom (Lee et al. 2010). Their findings revealed that attitude toward the behaviour, subjective norm and perceived behavioural control all were significant predictors of teachers' intention in using computers to create and deliver 
lessons, and suggests that teachers must have positive attitudes about it. Though a few studies have been done focusing on learner participation or m-learning intention, the study of students' English learning intention and affecting factors behind it is far from being adequate, especially in China with the largest population in English learning.

This study focused on Macao college freshman students' attitudes, subjective norms, and perceived behavioural control towards English learning. These factors were thought as significantly positively related to students' English learning intention. Furthermore, the study looked into the impact of students' gender and past-study place on their intention to learn English.

\section{Method}

This study employed a quantitative approach to collect data on Chinese college freshman students' attitudes, subjective norms, and perceived behavioural control towards English learning. A self-administered questionnaire was developed based on a comprehensive literature review. This questionnaire consisted of four sections, and a 7-point Likert scale was used. The first section related to demographic characteristics; the second section was associated with the identification of Theory of planned behaviour involving attitude, subjective norm, perceived behavioural control and behavioural intention. Respondents were asked to rate their level of agreement that ranged from $1=$ strongly disagree to $7=$ strongly agree.

Based on intensive reviews of previous studies, the following null hypotheses were proposed:

$\mathrm{H}_{1}$ : College students' attitude, subjective norms and perceived behavioural control towards English learning have no significant impact on their intention to learn English.

$\mathrm{H}_{2}$ : College students' gender has no significant impact on their attitude, subjective norms, perceived behavioural control and behavioural intention.

$\mathrm{H}_{3}$ : The places of learners' previous studies have no significant impact on their attitude, subjective norms, perceived behavioural control and behavioural intention.

\subsection{Participants}

This study used purposive sampling. The participants were all Macao college freshmen from different universities, such as the University of Macao, the City University of Macao, and the Macao University of Science and Technology. The pilot study was conducted at the City University of Macao in the first week of January 2019. After the pilot study was conducted, the questionnaire was checked whether the wording and meaning of statements were clear for the participants. After modifying some unclear words and phrasings in the questionnaires, the finalized version of the questionnaire was then distributed to all universities and colleges in Macao in an electronic format office 365 form.

After conducting the data collection of the study, 552 questionnaires were received from the 10th of February to the 10th of May. Eight invalid surveys were excluded due to some blank or multiple answers to the same questions. A total of 544 valid questionnaires were used for data analysis. Thus, the response rate was almost $99 \%$. 


\subsection{Instruments}

The pilot study adopted Cronbach's alpha to measure the internal consistency reliability of the questionnaire. The results showed that Cronbach's alphas for attitudes, subjective norms, and behavioural intention were high $(\alpha>.80)$, indicating high internal consistency of the questionnaire. The convergent validity factor loading beta values were high and statistically significant $(\beta>.80, p>.05)$, indicating that the questionnaire items were related and valid.

The 8 items measuring learners' attitude, 10 items measuring subjective norms including injunctive and descriptive norms, and 8 items measuring perceived behavior control including self-efficiency and autonomy were factors analysed with varimax rotation using Principal Component methods. The Principal Component Analysis with eigenvalues greater than one was rotated by the Varimax analysis. Only factor loadings of .05 or higher were retained, indicating good correlations between the items and the factors to which they belonged.

\section{Results}

$\mathrm{H}_{1}$ : College students' attitude, subjective norms and perceived behavioural control towards English learning have no significant impact on their intention to learn English.

Table. 1. Correlations between the selected variables and students' behavioural intention

\begin{tabular}{|l|l|l|l|l|}
\hline Variable & Mean & SD & N & Correlation \\
\hline Attitude & 4.84 & 1.30 & 552 & $0.57 * *$ \\
\hline Subjective norms & 5.20 & 1.18 & 552 & $0.64 * *$ \\
\hline $\begin{array}{l}\text { Perceived behavioural } \\
\text { control }\end{array}$ & 4.79 & 1.33 & 552 & $0.71 * *$ \\
\hline Behavioural intention & 5.52 & 1.40 & 552 & 1 \\
\hline
\end{tabular}

$* *$ Correlation is significant at the 0.01 level (2-tailed).

The results presented in Table 1 indicated a moderately positive correlation between students' attitude and their intention to learn English, $r(550)=.57, p<.01$. Similarly, the positive correlations were also found between subjective norms and students' behavioural intention, $\mathrm{r}(550)=.64, \mathrm{p}<.01$, perceived behavioural control and students' intention to learn English, $\mathrm{r}(550)=.71, \mathrm{p}<.01$. These results indicated that students' intention to learn English could be significantly improved with the improvement of students' attitude, subjective norms and perceived behavioural control.

Furthermore, Macao college students' subjective norms (injunctive) was more influential to their behavioural intention in comparison with subjective norms (descriptive). That is, the behavioural intention of learners resulted from their subjective norms (injunctive). In other words, learners engaged in the behaviour were mostly influenced by their families, 
friends or teachers. Furthermore, as for perceived behavioural control, Macao college students' self-efficacy is a more influential factor which affects their behavioural intention in comparison with autonomy. That is, Macao college students' self-efficacy allows them to have their personal judgments on their ability to learn English and evaluate if it could enable them to attain their goals. As a result, we suggest that establishing communication channels between teachers and students is very necessary, as it could help Macao college students to build up their subjective norms and self-efficacy.

H2: College students' gender have no impact on their attitude, subjective norms, perceived behavioural control and behavioural intention.

Table 2. Descriptive statistics of gender differences

\begin{tabular}{|l|l|l|l|l|}
\hline Variable & $\mathrm{t}$ & Sig. & Df & $\begin{array}{l}\text { Mean } \\
\text { Difference }\end{array}$ \\
\hline Attitude & 1.903 & 0.058 & 550 & 0.21015 \\
\hline Subjective norms & 2.944 & 0.003 & 550 & 0.29493 \\
\hline $\begin{array}{l}\text { Perceived behavioural } \\
\text { control }\end{array}$ & 2.902 & 0.004 & 550 & 0.32693 \\
\hline Behavioural intention & 3.665 & 0.000 & 550 & 0.42920 \\
\hline
\end{tabular}

The results in Table 2 showed that female hold a better attitude than male as their mean was higher (4.95>4.74), while standard deviation was lower $(1.25<1.34)$. The similar results could be found in the other variables, which illustrated that these female students performed better than the male students in subjective norms and perceived behavioral control. A further test was adopted to examine whether such differences are significant in general. Independent-Samples $\mathrm{T}$ Test was used to compare means of a dependent variable between female group and male group.

Table 3. Independent sample t-test between female and male

\begin{tabular}{|l|l|l|l|l|l|}
\hline Variable & Gender & N & Mean & SD & Std. Error Mean \\
\hline Attitude & Female & 272 & 4.9490 & 1.25322 & 0.07599 \\
\cline { 2 - 6 } & Male & 280 & 4.7388 & 1.33884 & 0.08001 \\
\hline \multirow{3}{*}{ Subjective norms } & Female & 272 & 5.3474 & 1.11887 & 0.06784 \\
\cline { 2 - 6 } & Male & 280 & 5.0525 & 1.23046 & 0.07353 \\
\hline \multirow{2}{*}{$\begin{array}{l}\text { Perceived behavioural } \\
\text { control }\end{array}$} & Female & 272 & 4.9582 & 1.26924 & 0.07696 \\
\cline { 2 - 6 } & Male & 280 & 4.6313 & 1.37378 & 0.08210 \\
\hline Behavioural intention & Female & 272 & 5.7408 & 1.38018 & 0.08369 \\
\cline { 2 - 6 } & Male & 280 & 5.3116 & 1.37078 & 0.08192 \\
\hline
\end{tabular}

As shown in the above table, the results revealed that there was no significant difference 


\section{Mll Macrothink}

between genders in attitude because its $p$-value $(p=0.058)$ is not lower than 0.01 . By the contrast, significant difference was found between female students and male students in subjective norms $(\mathrm{t}=2.94, \mathrm{df}=550)$, perceived behavioural control $(\mathrm{t}=2.90, \mathrm{df}=550)$, and behavioural intention $(3.67, \mathrm{df}=550)$.

H3: The places of learners' previous studies have no significant impact on their attitude, subjective norms, perceived behavioural control and behavioural intention.

Table. 4. Descriptive Statistics of area differences

\begin{tabular}{|l|l|l|l|l|}
\hline Variable & $\mathrm{t}$ & Sig. & Df & $\begin{array}{l}\text { Mean } \\
\text { Difference }\end{array}$ \\
\hline Attitude & 5.031 & 0.000 & 348 & 0.57325 \\
\hline Subjective norms & 9.432 & 0.000 & 538 & 0.94429 \\
\hline $\begin{array}{l}\text { Perceived behavioural } \\
\text { control }\end{array}$ & 7.658 & 0.000 & 348 & 0.87021 \\
\hline Behavioural intention & 9.978 & 0.000 & 538 & 1.16707 \\
\hline
\end{tabular}

As demonstrated in Table 4., among the participants ( $\mathrm{N}=552)$, mainland students occupied $67.21 \%(\mathrm{~N}=371)$, while students from Macao occupied 30.62\% ( $\mathrm{N}=169)$. In average, mainland students got a higher score than the students from Macao in the aspects of attitude, subjective norms, perceived behavioural control and behavioural intention. Particularly, the data indicated that mainland students performed better than the students from Macao in subjective norms as they got a lower standard deviation $(1.06<1.12)$.

Table. 5. Independent sample t-test between Mainland China and Macao SAR

\begin{tabular}{|l|l|l|l|l|l|}
\hline Variable & Area & $\mathrm{N}$ & Mean & SD & Std. Error Mean \\
\hline \multirow{3}{*}{ Attitude } & Mainland China & 371 & 5.0451 & 1.28905 & 0.06692 \\
\cline { 2 - 6 } & Macao SAR & 169 & 4.4719 & 1.19894 & 0.09223 \\
\hline \multirow{3}{*}{ Subjective norms } & Mainland China & 371 & 5.5070 & 1.05869 & 0.05496 \\
\cline { 2 - 6 } & Macao SAR & 169 & 4.5627 & 1.12190 & 0.08630 \\
\hline \multirow{2}{*}{$\begin{array}{l}\text { Perceived behavioural } \\
\text { control }\end{array}$} & Mainland China & 371 & 5.0869 & 1.28466 & 0.06670 \\
\cline { 2 - 6 } & Macao SAR & 169 & 4.2167 & 1.19605 & 0.09200 \\
\hline Behavioural intention & Mainland China & 371 & 5.8949 & 1.27279 & 0.06608 \\
\cline { 2 - 6 } & Macao SAR & 169 & 4.7278 & 1.23257 & 0.09481 \\
\hline
\end{tabular}


The above table presented that there is a significant difference between students from Mainland China and Macao in attitude $(\mathrm{t}=5.03, \mathrm{df}=348)$, subjective norms $(\mathrm{t}=9.432, \mathrm{df}=538)$, perceived behavioral control $(\mathrm{t}=7.658, \mathrm{df}=348)$ and behavioural intention $(\mathrm{t}=9.978, \mathrm{df}=538)$. These results indicate that different contexts of students should be considered as a factor to impact students' attitude, subjective norms and perceived behavioural control towards English learning, as well as their intention to learn English.

\section{Discussion}

Research question 1: What factors do college freshmen in Macao consider important in English learning?

Following the TPB, Macao college freshmen consider attitudes towards English learning, subjective norms, and perceived behaviour control very important in their English learning. Positive attitudes towards English learning will undoubtedly lead to students' active engagement in their studies and facilitate their learning. Other important people like parents and teachers also have a big influence on students English learning. If parents are good at their English, their kids will be encouraged and work hard in their English lessons. Moreover, parents' encouragement will further motivate them and keep them enthusiastic in their studies. If the students are very confident about their ability in English learning, they are more likely to study English well.

Research question 2: What is the relationship between those factors in Macao college freshmen' English learning?

Macao college freshman students' attitudes towards English learning, subjective norms and their perceived behavioural control has positive relationship with their English learning intention. Firstly, Attitudes do significantly influence students' behaviour towards English learning. For Macao college freshmen, learning English is enjoyable and beneficial, which boosts their positive attitude. The reason is that the teaching methods applied in Macau is more practical, and English learning is perhaps more interactive and focused on speaking, while the teaching methods in high school are more memorisation and examination-oriented, and might cause the participants, most originating from Mainland China, to embrace this new and different approach more positively. Since students manifest affective attitudes towards their English learning, they are more willing to learn English well so as to add value to their "linguistic capital" (Block \& Cameron, 2002:5) which will increase their employability in the future. This reconfirms the finding of Ming et al. (2011) that the students' positive attitudes towards English learning will spur their desire to learn the language.

Secondly, Subjective norms have a positive relationship with Macao college freshman students' English learning intention. Family members play a big role in students' engagement in their English study. Especially, parents' active participation has proven to be the most influential factor in children's success in their English learning. It is in accordance with the 
founding of Gopala et al. (2014) that parental encouragement and support is correlated with students' positive attitudes towards English learning. Teachers also are acknowledged as impacting student's engagement in learning. The interactions between teachers and students in a classroom environment are linked to academic level and performance, and their positive relationships will cause students to pursue better academic results.

When we further investigate the subjective norms, we found that descriptive norms are more significant than injunctive norms. Thirdly, Macao college freshman students' perceived behavioural control also has a significantly positive relationship with their English learning intention.

Furthermore, comparing to autonomy, self-efficacy is more influential towards their behavioural intention towards English learning. More specifically, students' self-efficacy allows them to have personal judgments on their ability and to evaluate if it enables them to attain their goals. As for the students' autonomy, it obtained a lower level of impact in comparison with self-efficacy towards behavioural intention. Because many Macao college freshmen are passive English learners, and only learn English when they are asked to do so. So to increase their learning intention, English teachers should encourage students to learn by adopting appropriate teaching materials, strategies and methods to motive their learners.

Research question 3: Are there gender and place differences among those factors in college freshmen' English learning?

Yes, there are. Female freshmen present higher levels of behaviour intention when compared to their male classmates. They are also more influenced by how others perceive learning English and encourage them in such behaviour. A reason for this outcome could be cultural and historical. From ancient to modern times, although women's status in society has highly improved, women still do not possess enough equality in all corners of the society because China is still heavily influenced by Confucian and traditional dogmas and ideas. Therefore, female students might need more encouragement to engage in certain behaviours when compared to male students. Progress has been made as the Chinese Communist Party encouraged women to participate more actively in a new socialist nation. However, the reality is that Chinese society is still mainly male governed. Women, therefore, need to be more persistent and determined to achieve academic success when compared to male students. The result also shows that the perceived behavioural control of female college students is significantly higher than that of male students. Our finding is similar to the previous studies of Oxford and Burry-stock(1995), Chien \& Wei(1998), and Wharton(2000), which suggests that female students have better language ability. It also shows that female students' subjective norm is significantly higher than male students'. Besides, female learners also obtain a higher level of behavioural intention in comparison with male students. This result is similar to previous studies such as the studies of Compeau \& Higgins (1995) and Ehrman, et al. (2003). In conclusion, the greater the perceived behavioural control of female students is, the more favourable the subjective norms and attitude of female students are, the higher their behavioural intention of female students will be. 


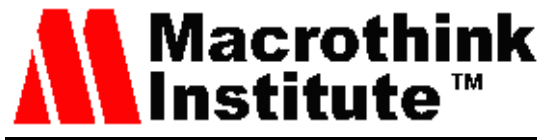

The result also shows that students from Mainland China who previously studied English in Mainland China revealed a more positive attitude for English learning than local students. Reasons for this could be related to the different teaching and learning approaches between Mainland China and Macau. The Chinese education departments place greater prominence on the school's English Education. Continuous efforts have been made to improve teaching methods and techniques. This has a significant impact on college students' studying willingness and attitudes. While in Macao, even in Portuguese colonial ruling era, English did not have an efficient environment to develop. Only in the recent 20 years, due to the rapid economic growth, has the English taken a more predominant role in Macau's society and education. Comparing to Macao local students, the competition to enter the best schools and universities in mainland China is intense and competitive, English being one of the main subjects that are tested. This drives the mainland students to acknowledge and embrace the learning of English greatly when compared to Macao local students. For some students, their purpose of learning English well is to go abroad to further their education in English speaking countries like the U.S., U.K., Australia, Canada. After all, language competence is an essential communication skill to create more economic values to college students and ensure their bright future.

The results revealed something interesting in language learning contexts that Mainland Chinese students are more influenced by their family members. Mainland Chinese families perhaps enhance the importance of dominating the English language, more so than Macanese families. Economic reasons could be behind such a revelation. Chinese economic growth is greatly linked to internationalisation, business dealings with foreign companies and corporations, where the English language is used as the medium for communicating and negotiating. The economy of Mainland China is currently developed very fast; a lot of international companies have sprung up. The mastering of good English language skills has been essential for working in those companies so that students from Mainland China would spare their great efforts on their English learning to enhance their competitiveness. Macau, on the other hand, has its economy intrinsically tied to the tourism industry and has been considered as a tourist destination with most tourists from Mainland and Hong Kong. Of the 35 million tourists visiting Macau in 2018, 25.26 million originated from Mainland China, most to engage in gaming at the casinos. ${ }^{1}$ It is safe to assume that having good communication skills in Mandarin surpasses the importance of the English language when accommodating such a large Chinese tourist population. Under this circumstance, the learners in Macao might lack interest in English learning since the labour markets do not require much foreign language competence. When Macao becomes a world leisure and tourism destination, Macao local students will have to equip themselves well to face the transition to internationalisation. It is suggested that English language teaching and learning in Macao should be enhanced in different levels of schooling to prepare Macao local students for future markets

\footnotetext{
${ }^{1}$ Retrieved from: https://www.dsec.gov.mo 2019.
} 


\section{Conclusion}

The purpose of this study is to investigate different factors on Macao college freshman students' English learning and their behavioural intention. Under the framework of TPB, we concluded that there is a significantly positive relationship between attitudes, subjective norms, perceived behavioural control and behaviour intention.

This study has successfully explored factors behind Macao college freshman students' English learning intention and shed new lights on student's engagement in learning English in Macau's tertiary institutions. To improve Macao college students' English efficiency, it is important to enactive the following factors involved in their English learning intention. On the one side, Teachers should highlight the importance of learning English and its positive outcomes at an early stage of students' school formation. English should be considered the main learning objective in the classrooms of Macao in their early stages. New teaching methodologies and strategies should be introduced to trigger and motivate students to learn English. Teachers should be trained and encouraged to welcome such new methodologies and strategies, while students should be gradually introduced to such practices and form a positive attitude towards English learning. Teachers also should have good communication with their students and reassure that they can learn English well to develop their self-efficacy. On the other side, parents and relatives should be encouraged to actively participate in their children's English proficiency development. Students should feel the positive support of their parents and other families providing more encouragement, and they should be willing to improve their English skills. As for the Macao government, it is imperative that a more English driven education in schools is prioritised. Snice Macao is building up into a world centre of tourism and leisure and a more internationalised society, the government should enhance the importance of English together with its official languages. The future society must welcome those with more than one language competence and efficient intercultural communication skills.

\section{Acknowledgments}

This study was funded by the Macau Foundation (MF1819). We thank Dr Yingjuan Wang, Pedro Paulo dos Santos, Helice Yin, Daniel Leong and Iris Mak for their help in questionnaire designing and data collecting.

\section{References}

Ajzen, I. (1991). The theory of planned behaviour. Organisational and Human Decision Processes, 50(2), 179-211. https://doi.org/10.1111/weng.12053

Ajzen, I. (2001). Nature and operation of attitudes. Annual Review of Psychology, 52(1), 27-58.

Ajzen, I. (2002). Perceived behavioural control, self-efficacy, locus of control, and the theory of planned behaviour. Journal of Applied Social Psychology, 32(4), 665-683. 


\section{MInstitute Macrothink $_{\text {Int }}$}

Ajzen, I. (2006). Behavioral Interventions Based on the Theory of Planned Behavior. http://people.umass.edu/aizen/pdf/tpb.intervention.pdf

Ajzen, I. (2012). Theory of planned behaviour. In P.A. Van. Lange, A. W. Kruglanski, \& E. T. Higgins (Eds.), Vol. I Handbook of theories of social psychology (pp. 438-459). SAGE.

Ajzen, I. (2014). The theory of planned behaviour is alive and well, and not ready to retire: a commentary on Sniehotta, Presseau, and Araujo-Soares. Health Psychology Review, 9(2), 131-137.

Banisaeid, M., \& Huang, J. (2015). The role of motivation in self-regulated learning and language learning strategy: In the case of Chinese EFL learners. International Journal of Applied Linguistics and English Literature, 4(5), 36-43.

Block, D., \& Cameron, D. (Eds) (2002). Globalisation and Language Teaching. London: Routledge.

Botha, W. (2013). English-medium instruction at a university in Macau: Policy and realities. World Englishes, 32(4), 461-475. https://doi.org/10.1111/weng.12053

Bray, M., Butler, R., Hui, P., Kwo, O., \& Mang, E. (2002). Higher education in Macau: growth and strategic development. Comparative Education Research Centre, the University of Hong Kong.

Chen, I. J. (2004). An analysis of Taiwanese continuing education students' beliefs regarding language training: an application of the theory of planned behavior. [Doctoral Dissertation]. Research University of Idaho.

Cheon, J., Lee, S., Crooks, S. M., \& Song, J. (2012). An investigation of mobile learning readiness in higher education based on the theory of planned behavior. Computers and Education, 59(3), 1054-1064.https://doi.org/10.1016/j.compedu.2012.04.015

Chien, C., and Wei, L. (1998). The strategy use in listening comprehension for learners in Taiwan. RELC Journal, 29(1), 66-94. https://doi.org/10.1177/003368829802900105

Compeau, D. R. \& Higgins, A. C. (1995). Application of social cognitive theory to training for computer skills, Information systems research, $6(2)$, 118-143.https://doi.org/10.1287/isre.6.2.118

Ehrman, M. E., Leaver, B. L., \& Oxford, R. L. (2003). A brief overview of individual differences in second language learning. System, 31(3), 313-330. https://doi.org/10.1016/s0346-251x(03)00045-9

Fishbein, M., \& Ajzen, I. (2011). Predicting and changing behavior: The reasoned action approach. Taylor \& Francis.

Fan, C. W., \& Ho, K. K. (2012). A tale of three cities: Review of the development of ICT in school education between Hong Kong, Macau and Singapore. New Horizons in Education, 60(1), 70-82. 


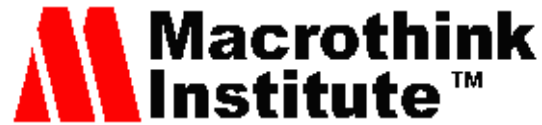

Girardelli, D., \& Patel, V. K. (2015). The theory of planned behavior and Chinese ESL students' in-class. participation. Journal of Language Teaching and Research, 7(1), 31-41. https://doi.org/10.17507/jltr.0701.04

Hagger, M., \& Chatzisarantis, N. L. (2005). First-and higher-order models of attitudes, normative influence, and perceived behavioural control in the theory of planned behavior. The British Psychological Society, 44(4), 513-535. https://doi.org/10.1348/014466604x16219

Ip, W.S., Feez, S., Zhang, Z., \& Ngo, T. (2016). University students' beliefs about English learning and their use of learning strategies: a mixed-method study in Macao. [Doctoral Dissertation]. Research University of New England. https://hdl.handle.net/1959.11/19921

Lee, J., Cerreto, F. A., \& Lee, J. (2010). Theory of planned behavior and teachers' decisions regarding use of educational technology. Educational Technology \& Society, 13(1), 152-164. http://www.ifets.info/journals/13_1/15.pdf

Leong, M. W., \& Li, X. (2011). Optimised strategy in English teaching for tourism management major-based on the analysis of the behavioural characteristics of English Learning in tourism management major of Macau University of Science and Technology. Tourism Tribune, 26(2), 89-94.

McEachan, R. R. C., Conner, M., Taylor, N., \& Lawton, R. J. (2011). Prospective prediction of health-related behaviors with the Theory of Planned Behavior: A meta-analysis. Health Psychology Review, 5(2), 97-144. https://doi.org/10.1080/17437199.2010.521684

Monteiro, E., \& Tchiang, I. (2017). English language teaching and learning in five local secondary schools in Macao. Paper presented in ICLLCE $9^{\text {th }}$. https://pdfs.semanticscholar.org/375e/08b5879125c44c59030c74771908c796f596.pdf

Moody, A. (2008). Macau English: Status, functions and forms. English Today, 24(3), 3-15. https://doi.org/10.1017/s0266078408000242

Oxford, R., \& Burry-Stock, J. A. (1995). Assessing the use of language learning strategies worldwide with the ESL/EFL version of the Strategy Inventory for Language Learning (SILL), System, 23(1), 1-23.

Shi, L. (2006). The successors to Confucianism or a new generation? A questionnaire study on Chinese students' culture of learning English. Language, Culture and Curriculum, 19(1), 122-147. https://doi.org/10.1080/07908310608668758

Statistics and Census Service DSEC, Data retrieved from https://www.dsec.gov.mo/Statistic.aspx?NodeGuid=8d4d5779-c0d3-42f0-ae71-8b747bdc8d8 8

Thang, S. M., Ting, S. L., \& Nurjanah, M. J. (2011). Attitudes and motivation of Malaysian secondary students towards learning English as a second language: A case study. The Southeast Asian Journal of English Language Studies, 17(1), 40-54. http://ejournal.ukm.my/31/article/view/974 


\section{Macrothink}

Venkatesh, V., \& F. D. Davis. (2000). A theoretical extension of the technology acceptance model: four longitudinal field studies. Management Science, 46(2), 186-204. https://doi.org/10.1287/mnsc.46.2.186.11926

Venkatesh, V., Morris, M.G., \& Ackerman, P. L. (2000). A longitudinal field investigation of gender differences in individual technology adoption decision-making processes, Organizational Behavior and Human Decision Processes, 83(1), 33-60. https://doi.org/10.1006/obhd.2000.2896

Vong, S. K., \& Wu, J. (2010). The way out for the education reform in Macao-an analysis of the school-based curriculum development in Macao. Southwest University (social sciences), 36(2), 80-83.

Wharton, G. (2000). Language learning strategy use of bilingual foreign language learners in Singapore. Language Learning, 50(2), 203-243. https://doi.org/10.1111/0023-8333.00117

Young, M. Y. C. (2006). Macao students' attitudes toward English: a post-1999 survey. World Englishes, 25(3-4), 479-490. https://doi.org/10.1111/j.1467-971x.2006.00468.x

Young, M. Y. C. (2009). Multilingual education in Macao. International Journal of Multilingualism, 6(4), 412-425. https://doi.org/10.1080/14790710802152438

\section{Copyright Disclaimer}

Copyright for this article is retained by the author(s), with first publication rights granted to the journal.

This is an open-access article distributed under the terms and conditions of the Creative Commons Attribution license (http://creativecommons.org/licenses/by/3.0/). 